\title{
Postmodernist Genre in Science Fiction
}

\author{
Dr. Amjad Mofleh Salim Al-Khlaifate \\ Assistant Professor of English Literature Sajir College of Science and Arts, Shaqra University, Saudi Arabia
}

\begin{abstract}
Science Fiction is the literature of change. Another widely-held view is that Science Fiction is fiction that describes the impact of science or technology on people. The current paper is intended to exploring human potential and speculating about mankind's problems and their possible solutions. The discussion led to the facts that science fiction is fully imagined and well research can provides us with a road map for the future and it can become a kind of "testing ground" wherein new innovations and the implications surrounding them can be explore ahead of time.
\end{abstract}

\section{Introduction}

Postmodernist Genre in Science Fiction is an interaction between Nature and technology has become a key issue and the boundary between the biological and the technological is opened to repeated question. Further, the postmodern preoccupation with language and textuality has led to an insistently periodic culture and this has led to postmodernist authors to adopt generic modes which can be exploited for their familiarity but at the same time deconstructed and extended in unfamiliar often unknown directions and into new generic formulations. Similarly, science fiction has been exploited to explore ontological boundaries.

According to Jaques Derrida a genre is a paradoxical entity for as soon as the word genre is uttered it tends to draw a limit but as soon as the line is drawn or a limit established innovations are not far behind. The same is the case with science fiction as a genre. Once decided what would go into the definition, the norms were expanded to include more. So the law of the genre implies both simultaneously formativeness and end of norms. Jean-François Lyotard takes this 'end' to be apocalyptic, the collapse of metanarratives and archetypes, and no metalanguage that has a reliable nature.

\section{Discussion}

In science fiction, as in US culture generally, the 1970s and early 1980s were a period of heroic, aggressive internationalism. The Baby Boom had reached college, and the Civil Rights and anti-war movements inspired in them an almost romantic solidarity with other cultures. Publishers felt that not only European but Latin American and even Japanese and African literature had markets. In science fiction, too, there was a minitranslation boom. Macmillan was committed to publishing several Soviet science fiction novels, and it seemed that the whole Strugatsky oeuvre might soon appear in English. Seabury, and later Avon, published Lem as though he were the Polish Borges. As the new branch of sophisticated science fiction inaugurated by the British New Wave became established in the US, it appeared that literary science fiction from Europe and the USSR would come to share in its glory.

But even then there were troubling lacunae. Where were Japanese and Chinese science fiction, which we knew existed but seldom saw in translation? Was there no science fiction in the Third World? Anthologies of Japanese and Chinese science fiction did finally appear in English, but they are the last such gatherings listed by James Gunn in his introduction to the new global science fiction volume of The Road to Science Fiction. The past ten years have seen a drastic decline in US publication of "foreign" science fiction, and looking back from 1989, there hadn't actually been that much non-Anglo science fiction published in English after all. Aside from the Strugatskys, Lem, and the Macmillan Soviets, what was the tally? In terms of novels (by then the main medium for science fiction), a few by Gérard Klein, another few by Michel Jeury and Pierre Boulle and Robert Merle, a handful by Wolfgang Jeschke and Herbert Franke, one by Sakyo Komatsu (abridged), Kobo Abé's Inter Ice Age 4 (1959; US 1970), and perhaps a few others. Some classics were re-translated (Verne, Čapek, Zamyatin, Bulgakov) or appeared for the first time from university presses (Villiers de l'Isle-Adam, Alexander Bogdanov). But that was it.

The state of the art in 1999 is wretched. Almost all the international anthologies and stand-alone novels are out of print and/or inaccessible. Gunn's volume 6 of The Road to Science Fiction, entitled Around the World, and Franz Rottensteiner's reissue of View from Another Shore, originally published in 1973, are recent attempts to keep non-Anglo voices alive in English. Each book has its virtues, but ultimately each merely underscores how completely Anglo science fiction has consolidated its dominance over the genre. 
Gunn's anthology is an interesting addition to his big project of collecting exemplary stories from every period, and now every major region, of science fiction. Its superlatively classy cover displays a list of some of the most illustrious writers ever associated with science fiction: Abé, Borges, Calvino, Capek, Carlos Fuentes, E.T.A. Hoffman (sic), Kafka, Lem, García Márquez, the Strugatskys, Verne, Ye Yonglie. The selections inside are arranged according to regions: France (Verne, Albert Robida, J.-H. Rosny Aîné, Boris Vian, Philippe Curval, and Gérard Klein, with Elisabeth Vonarburg representing Québec), Germany (Hoffmann, Kurd Lasswitz, Kafka, Herbert W. Franke, Wolfgang Jeschke, Erik Simon), Scandinavia and Finland (Svend Åge Madsen, Sam J. Lundwall), Eastern Europe (Capek, Lem, Josef Nesvadba, Alexandr Kramer, Ovid S. Crohmalniceanu), Russia (the Strugatskys, Kirill Bulychev), Italy (Dino Buzzati, Tommaso Landolfi, Italo Calvino), Spain and Latin America (Teresa Inglés, Borges, García Márquez, Fuentes), India (Laxman Londhe), China (Zheng Wenguang, Ye Yonglie), and Japan (Abé, Komatsu, Tetsu Yano)--with an appended biographical mini-essay by Elisabeth Vonarburg. Obviously, it is an impressive gathering, but the ultimate effect is of a wellintentioned mélange of pre-, proto-, para-, and pulp science fiction that has little theoretical or practical coherence.

But what should the purpose of an anthology of "international science fiction" be? Should it show that other, more literary traditions produce works of science fictional beauty? Should it show that "foreign" writers write science fiction distinctive of their language-cultures? Should it show that science fiction is a global phenomenon that the pulp formulae travel everywhere, and that Sturgeon's Law is universal? How should one define "international science fiction" when the most popular and prolific forms come from a single culture, and the rest of the globe constitutes the periphery?

Whatever criterion an editor might use, the sad fact is that non-Anglo science fiction does not sell. Gunn offers cogent reasons for this commercial failure; the main one, curiously enough, cuts across his gallant intention "to recognize other traditions and, by bringing them together into a kind of gestalt of foreign science fiction, to provide a corrective to the illusion that all science fiction is American" (10). The problem is that Gunn's overall conception of the field seems almost calculated to justify true fans' distaste for "foreign" science fiction, since the "truth" is it's not really science fiction at all.

In The Road to Science Fiction, Gunn offers a most elegant definition of the genre. Science fiction for him "deals with the effects of change on people in the real world as it can be projected into the past, the future, or to distant places. It often concerns itself with scientific or technological change, and it usually involves matters whose importance is greater than the individual or the community; often civilization or the race itself is in danger" (16). For science fiction the world is knowable; human existence is an evolutionary outcome; and, armed with that knowledge, human beings are capable of influencing their further evolution. These qualities explain, to Gunn's mind, the great aesthetic and cognitive differences between science fiction and "mainstream" literature--or, as it eventually becomes, literature itself. "Mainstream" literature is preoccupied with the present, and concentrates on social interaction as if "the only important ... aspect of existence is the way in which people relate to each other" (20). In the course of his argument, Gunn imperceptibly elides his definition of science fiction with "American" science fiction--with its characteristic pragmatism and problem-solving--and his sketch of "mainstream" literature with European, and ultimately all non-Anglo, science fiction. The latter are "other" than US core-science fiction because they have been tied to the "literary" tradition rather than the pulp tradition that constitutes the distinctive formative environment of US science fiction. Non-US literature of the "serious" kind was congenial to the fantastic of all types, even science fiction, and so science fiction in more traditional literary cultures could not free itself from the constraints of archaic values that dominated traditional literature. Gunn cites good historical reasons for this (uneven development, the social fallout of the great wars, etc.)--but the fact remains that science fiction outside the US has been unable to develop those qualities that define "real" science fiction. It is more prone to social concreteness, to present-centeredness, to stylistic affectation reflecting psychological or literary complexity, and to fatalism in the face of history. Though Gunn does not want to state it, the conclusion is clear: the American science fiction fan cannot enjoy that "foreign stuff" because it isn't the real thing.

And of course he may be right. Most of his selections certainly do nothing to refute this idea. By choosing to organize the stories exclusively by region, Gunn avoids confronting the fact that most of his examples require a broader definition of science fiction--as, say, a class of fantasy writing that uses scientific ideas and fictive inventions for a myriad of metaphorical purposes, and of which the problem-solving heroism of the American pulps and Soviet socialist-futurism is a mere subset. Gunn could have chosen only science fiction texts consistent with his theory; instead, he collects several fine examples of literary fantasy that clearly elude narrow generic boundaries. Some writers, such as Borges, García Márquez, Kafka, Abé, and even Calvino, might be considered writers of anti-sf--rational fantasists who reject and deprecate the moral and aesthetic conventions of Gunn's problem-solving genre. There are also some examples of inventive, original science fiction by anyone's definition (such as Curval's "An Alien behind the Wine Bottle," Jeschke's "Loitering at Death's Door," and Tetsu Yano's lovely, lyrical "The Legend of the Paper Spaceship"). Organizing by regions 
and countries is merely a convenience--Gunn does not consider how the languages of national literatures might affect science fiction, and literatures for him run together as a sort of monolithic pre-scientific institution. So the only thing that national divisions can reflect in his scheme is a vague sense of "history." Accordingly, the historical examples--Verne, Robida, Lasswitz, Rosny Aîné, Hoffmann--might be useful, but only if they are placed specifically in the context of historical antecedents of science fiction. Moreover, such a collection would have to include more texts of obvious historical (as opposed to literary) significance: e.g., works by Konstantin Tsiolkovksy, Alexander Bogdanov, Alexei Tolstoy, Maurice Renard, Stanislaw Witkiewicz, Imre Madách, etc.

The Road to Science Fiction Vol.6 does not purport to be a purely historical anthology, nor even a theoretically consistent one. Still, "gestalts" don't just happen; they emerge from history and theory. As a result, Gunn's anthology is a grab bag of texts with different relations to both science fiction and "the world," selected to fill certain niches--nation, generic history, literary status--that do not really complement one another. In the end, Gunn never does provide a rationale for why these stories, and not others, should have been included.

Perhaps even more distressing than this theoretical confusion, the bibliographic apparatus (limited to an "Acknowledgments" page) is a mess. Sometimes translation dates are given, but not original publication dates; sometimes original publication venues are given, sometimes not; publication sites are absent altogether. Occasionally some of this information is supplied in the introductory comments before each selection, more usually not. In some cases, no information at all is provided about the translations (e.g., the selections from Verne, Robida, and Kafka). The edition from which Gunn has culled the translation of Hoffmann's "The Sandman" is given, but not the name of the translator. Because of this bibliographic chaos, it is also unclear how many of the selections were translated specifically for this volume. I can guess that all the entries "reprinted by permission of the author" and lacking English publication dates were commissioned (but what about Kafka's "The Hunter Gracchus," which is not listed at all in the "Acknowledgments"? Could Gunn have actually commissioned a new translation of this canonical Kafka story without mentioning it?). Another clue is that these particular stories (by Franke, Jeschke, Simon, Madsen, Nesvadba, Crohmalniceanu, and, yes, Kafka) were all "adapted by James Gunn"--though there is no explanation of what this "adaptation" entailed.

Elisabeth Vonarburg's short biographical appendix, "US, science fiction and Us," details her creative journey from an initial exposure to science fiction via the French Fleuve Noir series, through her increasingly fraught relationship with Anglo science fiction, complicated by her emigration to Québec. It is a rich and interesting story, but Vonarburg's ideas are surprisingly confused. For Vonarburg, science fiction, like science itself, "transcends cultural barriers"--partly because these barriers are breaking down under global Americanization, but also because the genre has a universal thesaurus of concerns and themes. She rejects the notion that authors or works of science fiction can have "cultural specificity" (654); yet on the next page, she speaks of the "fundamental originality and uniqueness of each writer's voice in her or his own language" (655). Language--how different languages and literary norms can define the boundaries of what a culture is used to imagining, and the challenge of making sense against those norms--is the factor that does not come up in Gunn's speculations, or for that matter in Vonarburg's. She does make it clear that all non-Anglo science fiction writers must adopt a complex attitude, working both with and against the dominant Anglo tradition. Yet she is very sketchy about how French and French-Canadian writers specifically work within fraught cultural traditions. The main problem, it seems to me, in Gunn's--and the US science fiction establishments--approach to the question of non-Anglo science fiction is that they do not think very deeply about language and how it may affect thought. This is a perfectly understandable (if lamentable) attitude on the part of the new lingua franca, Satellite English, as it drives other tongues to extinction.

Franz Rottensteiner is well aware of this Anglophone juggernaut. In his revised introduction to an old collection, Rottensteiner updates the condition of European science fiction since the fall of the Soviet order. The once-dignified (and subsidized) Eastern European alternatives to US models have been swept away by the tidal wave of inexpensive translations of American pulps. Publishers there (as here) know that there is no money in the native product, and the object of desire is whatever works in the US market. But if Rottensteiner's goal in 1999 is the same as it was in 1973 when this anthology originally appeared--i.e., to demonstrate the quality and vitality of European alternative-sf--it is poorly served indeed by republishing essentially the same selection of stories as in the original edition. Only a single story has been added, Wolfgang Jeschke's 1986 tale "The Land of Osiris"--significantly, one of the volume's finest selections. What other recent gems did Rottensteiner see fit not to include? It makes little sense that one of the leading editors and anthologists of European science fiction should not have found equally good or better stories written during the past twenty-five years. Far from demonstrating vitality, the book seems to say that European science fiction remains frozen in a sort of Golden Age. The stories are generally of much higher quality than those in Gunn's volume, but they do not represent a living tradition of European science fiction.

More bothersome than the apparent nonchalance of Rottensteiner's (non-) selection of stories is his introduction. After providing a solid explanation of science fiction's changed social situation in Central and Eastern Europe after the fall of Communism, the piece degenerates into a nearly ad hominem attack on 
Stanislaw Lem. The 1973 introduction had praised Lem highly (Rottensteiner was Lem's agent at the time for the anglophone regions), but now this praise has been replaced by scorn, perhaps reflecting the bitter controversy that has divided the two men in recent years. Rottensteiner blasts Lem on so many fronts that a reader coming to the subject for the first time would be simply clueless. What's the sense of expending several valuable pages trashing a writer whose reputation as a major artist few can contest, a reputation few have done more to build than Rottensteiner himself? Nothing in Lem's art has changed, no matter how grave his personal flaws may be, or how misanthropic and misogynistic his world-view. Nor does it make much sense to offer the Strugatskys as virtuous countermodels--especially since there are no Strugatsky stories in the collection.

Even with its rancorous introduction, its limited scope, and its anachronistic selections, View from Another Shore is still a better read than Gunn's anthology; but it does nothing to establish whether current European science fiction is a vital and evolving body of literature. Indeed, both anthologies show us only this: that there was once a branch of scientific-rational fantasy that national writers pursued in their own way, without anxiety about the power of American science fiction to control the world's science-fictional imagination as its political economy dominates the nations. But the real question of the moment is: how are the world's scientific fantasists responding to metropolitan American science fiction (diffused through the multinational film industry in the "international style" of science fiction-spectacle production) as it saturates once-national public cultures? What we really need to know is the state of the art in the global provinces, right now. On this crucial question, Gunn and Rottensteiner are quiet.

The postmodern preoccupation with language and textuality has led to as insistently periodic culture. As a result, postmodernist authors have been led to adopt generic modes which can be exploited for their familiarity but at the same time deconstructed and extended in unfamiliar and often much more sophisticated direction, sometimes introducing philosophical preoccupations which are alien to the genre. Paul Auster's detectives are like post modern flaneurs: nihilistic observers of New York, detached wanders and gazers at a city whose meaning baffles them. The incongruity that results from the collision of the populist and the philosophical is often comic, as in Tom Stoppard, but can also be exploited for political ends. The latter accounts for some of the uses which feminist writers have made of the Gothic mode. Similarly, science fiction has been exploited to explore the ontological boundaries of the human- boundaries which are in evidence in TV and cinema versions of the genre, for example, in the human/cybernetic boundary personified in the Borg in Star Trek.

Jacques Derrida is preoccupied, in his discussions of genre, with its paradoxical qualities. He says that: As soon as the work 'genre' is sounded, as soon as it is heard, as soon as one attempts to conceive it, a limit is drawn. And when a limit is established, norms and interdictions are not far behind: 'Do', 'Do not' say 'genre', the figure, the voice, or the law of genre.

For Jean-Francois Lyotard the notion of that 'end' acquires much bigger implications and is associated with an apocalyptic post modernity. For him, genre is linked to his concept of the 'different', which is 'a case of conflict' which 'cannot be resolved for lack of a rule of judgment applicable to botharguments'. The background to this is that the collapse of metanarratives (which I discussed in the Introduction) leaves only a range of competing narratives, each of which has as much legitimacy as any other. This means that there can be no metalanguage in which a thoroughly reliable judgment can be made.

Lyotard's focus is on legal and political questions but his discussion of genre in the context of different is relevant to postmodern literature because is provides insights into the political reasons why that literature is so concerned to enact the fissures that open up between one genre and another. The impossibility of resolving the dispute arises because the dispute takes place as it were between genres so that a judgment cannot be made that would be just for both sides. To make such a judgment would be as impossible as ruling on a dispute between a character in a legal report and a character in romance. A universal genre, which would pro0vide the language required for resolving the dispute, is a unavailable as a grand narrative that explains all of human experience. So what is left is an urgent sense of generic relativity; the political task in the face of this is to detect different and to invent the idiom that is required to phrase them, even though such an idiom is ' impossible'.

This prevailing emphasis on impossibility is tied to a repeated and ambiguous sense of the apocalyptic in Lyotard- of being (half in hope, half ins despair) at the end of history:

Could it be that 'we' are no longer telling ourselves anything? Are 'we' not telling, whether bitterly or gladly, the great narrative of the end of great narratives? For thought to remain modern, doesn't it suffice that it thinks in terms of the end of some history? Or, is post modernity the pastime of an old man who scrounges in the garbage-heap of finality looking for leftovers, who brandishes unconscious nesses, lapses, limits, confines, gulags, parataxis, non-senses, or paradoxes, and who turns this into the glory of his novelty, into his promise of change.

Lyotard's concept of the different, his emphasis on the irreconcilable clash of linguistic worlds, works well when applied to Edwin Morgan's science fiction poems. The opportunity which the genre provides to enact the thoroughly bewildered encounter of irreconcilably different cultures is exploited by Morgan so that he invents 
radically disjunctive texts which display this irreconcilability linguistically. This connects these poems to Morgan's experience of writing sound and concrete poems, a point which is well illustrated in this book by the printing as one of its documents (p.164) of his 'emergent' poem ' Message Clear' - a poem I discuss in the Introduction. This avant-grade experience is drawn upon in the science fiction poems so that the visual and aural materials of language are thoroughly exploited in them.

This allows him, in 'The First Men on Mercury', to invent a literally impossible idiom for the aliens who inhabit the eponymous planet, and to juxtapose it with the English of the space-travelling earthlings, so that a different opens up between them in the space of their Lyotardian phrases in dispute':

-We come in peace from the third plane.

Would you take us to your leader?

- Bawr stretter ! Bawr. Bawr. Stretterhawl ?

The platitudinous and patronizing language of the earthlings reveals human complacency which is thoroughly unsettled by the profound alienness of the natives of Mercury. The two languages start of infect each other but so bewilderingly that it is frightening for both the earthlings and the mercurians, and desperately urgent that they leave each other to live separately in their irreconcilable other nesses.

Fredric Jameson compares science fiction to the historical novel, finding the two genres to be symmetrical opposites:

For it the historical novel ' corresponded' to the emergence of historicity, of a sense of history in its strong modern post-eighteenth century sense, science fiction equally corresponds to the waning or blockage of that historicity, and, particularly in our own time (in the postmodern era), to its crisis and paralysis, its enfeeblement and repression.

\section{Conclusion}

The argument is linked to Jameson's depiction of the loss of depth in post modernism and its accompanying multiplying of surfaces. What it fails to notice is the importance in the postmodern period of the historical novel as practiced by Gore Vidal, William Golding, Anthony Burgess, Rose Tremain, Margaret Atwood, Peter Ackroyd, Peter Carey and many others. Much of this writing takes a conventionally realist form and concerns itself hardly at all with the 'disappearance of the historical referent' (p.25) which Jameson considers to be a central preoccupation of American novelist E, L, Doctorow. Here, as elsewhere amongst postmodernist theorists, the internal demands of theorizing have led to a conspicuous ignoring of the contradiction in the culture and the variety of aesthetic practice. If historicity has been as enfeebled in the period as Jameson suggests, then this historical writing would not have been as vigorous and inventive as it has been; nor would it have found such a lucrative market.

Moreover, this negative view of the role of science fiction fails to take account of how important its resources have been to the postmodernist novel. Brain McHale is accurate in his substantial and detailed account of what the genre has meant to recent fiction, and his analysis of the symmetry between science fiction and postmodernism is illuminating:

Science fiction, like postmodernist fiction, is governed by the onto logical dominant. Indeed, it is perhaps the ontological genre par excellence. We can think of science fiction as postmodernism's no canonized or 'low art' double, its sister-genre in the same sense that the popular detective thriller is modernist fiction's sister-genre.

Novelists who have made important use of science fiction include William Burroughs, Kurt Vonnegur, the Angela Carter of Heroes and Villains and The Passion of New Eve, the Alasdair Gray of Lanark, the Marge Piercy of Body of Glass (which draws upon Donna J. Haraway's cyborg theorising) and the recent work of Will Self, especially Great Apes.

However, the most consistently powerful deployment of the genre has been in the work of J.G. Ballard, who started out in the 1960s writing inventive apocalyptic narratives, and developed, by the end of that decade, through The Atrocity Exhibition, an experimental collection of short pieces, into Crash, his most challenging and important work. Its challenge arises from its being sited on a different. Its central subject matter is car crashes: elsewhere in the culture these are conventionally treated, if at all, in the language of pornography and science fiction, and describing, in his characters, responses to it that combine fascination and sexual arousal, Ballard confronts his readers with a terrifying gap between generic world.

Science fiction is drawn upon generically, therefore, to provide the literary conventions that enable the invention of an alternative world in which norms are reversed. 


\section{References}

[1]. Clute, John, and Peter Nicholls. The Encyclopedia of Science Fiction. New York: St. Martin's, 1993.

[2]. Fabun, Don. "Science Fiction-News From the Hinter Worlds."

[3]. McNelly, Willes E. "Bradbury, 1920-." In Science Fiction Writers: Critical Studies of the Major Authors From the Early Nineteenth Century to the Present Day, edited by Everett Franklin Bleiler, 171-78. New York: Scribner's 1982.

[4]. McNurlin, Kathleen Woitel. "Question of Ethics: Themes in the Science Fiction Genre." Interdisciplinary Humanities 12, no. 4 (1995): 19-36.

[5]. Patrouch, Joe." Symbolic Settings in Science Fiction : H.G. Wells, Ray Bradbury, and Harlan Ellison." Journal of the Fantastic in the Arts I, no. 3(1988): 37-45

[6]. Pell, Sarah-Warner J. " Style Is the Man: Imagery in Bradbury's Fiction." In Ray Bradbury. edited by Martin Harry Greenberg and Joseph D. Olander, 186-94. New York: Taplinger, 1980.

[7]. Stockwell, Peter. "Language Knowledge, and the Stylistics of Science Fiction. "In Subjectivity and Literature from the Romantics to the Present Day, edited by Pilip Shaw and Peter Stockwell, 101-12, London: Pinter, 1991. 